Theme: Solidification / Casting

\title{
TUNDISH FLOW REGULATION WITH ADVANCED REFRACTORY DESIGNS*
}

\author{
Johan Richaud ${ }^{1}$ \\ William Chung ${ }^{2}$ \\ John Rogler
}

\begin{abstract}
Achieving high surface quality steel in the continuous casting process requires optimal mould level control. The design of the casting channel from the tundish to the mould is crucial to prevent formation of undesired instabilities or biased flows that can cause level fluctuation. With the aid of CFD and with physical water models, the geometry of the stopper nose and the nozzle seat have been studied and optimized to improve the overall mould flow stability. A special stopper nose; Ripple Stopper (RST), has been developed that reduces the formation of large and unwanted eddies in the liquid steel that destabilize the port exiting jets. Instead, the RST produces a fast release of turbulence in the form of a large number of small eddies. The large sudden fluctuations in the mould level are reduced, which in turn reduces the occurrence of surface defects. An additional benefit is derived from the local pressure around the stopper nose region being greater which reduces the refractory erosion. For a tundish gate type flow regulation, a new design encompasses an offset in the Tundish Well Nozzle (TWN) that realigns the flow and reduces the bias flow that is common to tundish gate regulation. The steel recirculation regions below the throttling gate are decreased reducing the risk of oxide depositions. The RST and the Offset bore casting channel have been applied successfully leading to a superior flow control performance between the tundish and the mould.

Keywords: Tundish stopper; Flow regulation; Offset Bore tundish gate; Ripple STopper ${ }^{\mathrm{TM}}$.
\end{abstract}

1 MASc and Engineering degree in Technical Ceramics, Global Technical Manager Flow Simulation, Vesuvius France, Feignies, France.

2 MASc, Masters of Applied Science in Mechanical Engineering, Flow Simulation Manager and Engineer North America, Vesuvius USA, Pittsburgh, USA.

3 MASc, Masters of Applied Science, Chemical Engineering, Flow Simulation Manager and Engineer North America, Vesuvius USA, Pittsburgh, USA.

* Technical contribution to the $45^{\text {th }}$ Steelmaking Seminar, May $25^{\text {th }}-28^{\text {th }}, 2014$, Porto Alegre, RS, Brazil. 


\section{INTRODUCTION}

During the modern steelmaking of continuous casting process, the molten metal is flowing from the ladle to the tundish and continuously from the tundish to the mould. This metal flow transfer is an key operation of continuous casting which affects strongly solidified shell profile, floatation of the non-metallic inclusion, mould flux entrainment by large meniscus level fluctuations.

In order to improve steel quality and to achieve a better flow control, design of the casting channel geometry in particular in the flow regulation region is critical.

The flow rate is controlled by restricting the opening with either a stopper rod comparable to a needle valve or a tundish slide gate. There is a wide variety of stopper nose geometries and throttling plate diameters with different degrees of sensitivity and controllability of steel flow.

Dimensions of the casting channel, the geometry of both the stopper nose / the nozzle seat or of the tundish nozzle / the throttling plate and the gas injection will influence the flow control performance.

\section{BACKGROUND}

Starting at the caster conception stages or revamping processes with the Original Equipment Manufacturer (OEM), the geometry of the casting channel and the design of the flow regulation devices are considered for the expected range of flow rates.

The main objective of a flow regulation system is to keep and maintain the level of molten metal in the mould constant, i.e. avoid large and sudden mould level fluctuations.

Controlling flow with a stopper rod is more difficult than with tundish slide gate because of the distance between the regulation region and the application of the control force, which is significantly longer in the case of stopper rod control system than of a tundish throttling plate. In addition the annular opening is more sensitive to displacement. But the benefit of a stopper rod flow control is that it reduces the risks of strand freeze-up at start-up if the preheating is considered. In addition the stopper delays the formation of a tundish vortex when the steel level is low. By construction, there is also less risk for air leakage possible when using a stopper than in the case of a multiple surfaces tundish gate system.

The flow inside the casting channel that includes a stopper is more uniformly distributed, so the mould flow will be more symmetrical than in the case of a conventional 2 or 3 plate tundish slide gate.

This article describes how design of flow control components can be optimized to produce stable mould flow. This will be achieved by producing a smoother flow regulation with a stopper and reducing flow asymmetries inside the casting channel when using a tundish slide gate.

\subsection{Stopper Regulation}

When considering a combination stopper and nozzle such as a Sub-Entry Nozzle (SEN), the relationship between steel flow rate and the vertical stopper position aka throughput versus stopper lift curve needs to be calculated.

To determine this relationship, the area of the open gap is first calculated from the stopper nose and nozzle seat geometry. Then the fluid velocity passing through the open area is calculated using Bernouilli's law. The steel flow rate can be deduced. It

* Technical contribution to the $45^{\text {th }}$ Steelmaking Seminar, May $25^{\text {th }}-28^{\text {th }}, 2014$, Porto Alegre, RS, Brazil. 


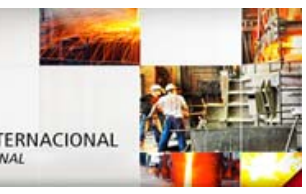

is general knowledge that the flow rate depends on the ferrostatic head in the tundish and on the casting channel bore size.

Theoretically the flow rate, $Q_{\text {th }}$, of the liquid has been estimated from the open area, $A_{o p e n}$, in the throttling or regulation region and the average velocity, $V_{t h}$, of the liquid steel flowing through the open area,

$Q_{\text {th }}=C_{D} \cdot A_{\text {open }} \cdot V_{\text {th }}$

with $C_{D}$ a coefficient of discharge. $C_{D}$ is comprised between 0.7 to 0.95 according to literature. $\mathbf{V}_{\text {th }}$ is determined from the height of steel, i.e. the ferrostatic head, $\mathrm{H}$ inside the tundish.

$\mathrm{V}_{\mathrm{th}}=\sqrt{2 \cdot \mathrm{g} \cdot \mathrm{H}}$

with $\mathrm{g}=$ acceleration due to gravity.

The open area of several stopper SEN system has been calculated by Bolger [1] and Bergman [2].

\subsection{Modeling of Stopper Regulation}

Water model of stopper regulation were realized in a full scale model composed by a $1 \mathrm{~m}$ tundish head tundish, a casting channel $75 \mathrm{~mm}$ in diameter and a distance of 0.9 $\mathrm{m}$ from the bottom of the tundish to the mould meniscus.

The water mould results highlight the shape of the regulation curve. An S-curve, red line in Figure 1, was measured. Field data was collected and confirmed the trend. The amplitude of the flow variation related to the open gap or stopper lift is reduced whenever liquid steel is cast. Due to the modeling similitude used; both Froude and Reynolds in a 1:1 water model, the differences in flow behavior could be related to the liquid density (difference in pressure gradients) and surface tension. These curves are showing that either the coefficient $C_{D}$ is not constant or the total ferrostatic head to consider is varying.

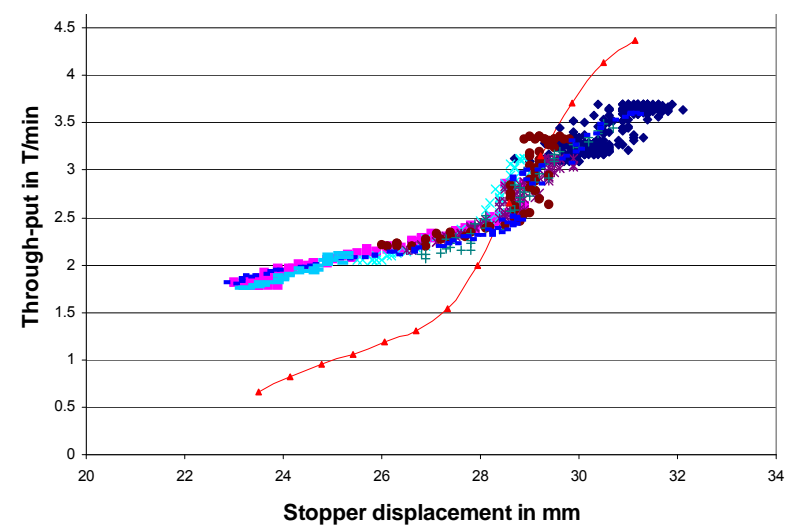

Figure 1. Stopper regulation curve in water (red) and in steel (plant data points).

\subsection{Numerical Simulations}

To better understand steel flow characteristics during casting and steel flow consequence on refractory performance, numerical simulation has been used. In particular, pressure along the refractory walls as well as the turbulence inside the casting channel need to be computed accurately.

Using Fluent, CFD software, a multi-radius stopper nose and a $70 \mathrm{~mm}$ diameter casting channel has been studied. The tundish head was $1 \mathrm{~m}$ and the distance from

* Technical contribution to the $45^{\text {th }}$ Steelmaking Seminar, May $25^{\text {th }}-28^{\text {th }}, 2014$, Porto Alegre, RS, Brazil. 
the bottom of the tundish to the mould meniscus was $0.8 \mathrm{~m}$. In Figure 2, the calculated stopper regulation curve -blue- is shown $0.8 \mathrm{~m}$. The stopper regulation curve is not linear but more closely resemble an S-curve and the Discharge Coefficient is not constant.

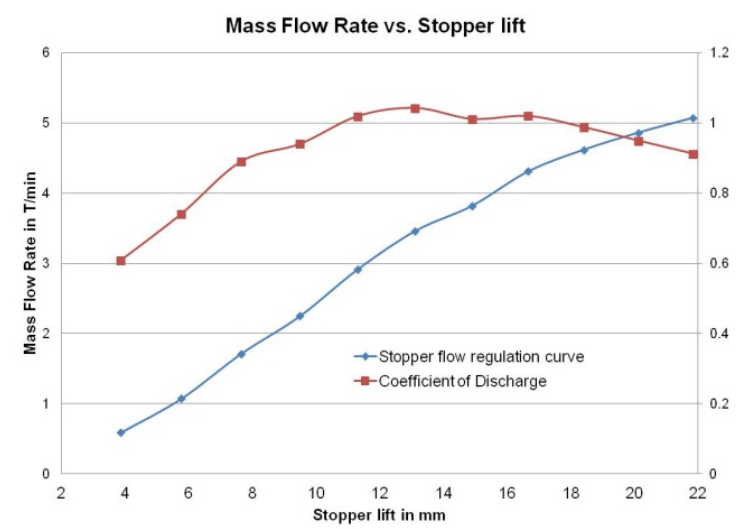

Figure 2. Calculated flow regulation and Discharge Coefficient curves.
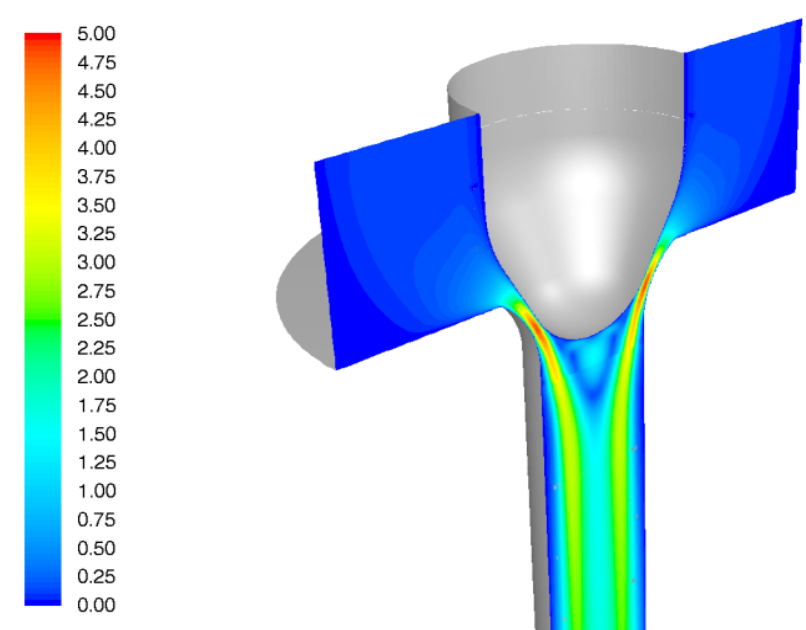

Figure 3. Contours of Velocity Magnitude expressed in $\mathrm{m} / \mathrm{s}$ of the liquid steel flowing through the aperture between the stopper nose and the nozzle seat at a given flow rate of $2.5 \mathrm{~T} / \mathrm{min}$.

Figure 4 displays a discharge coefficient versus stopper lift which is greater than 1 . This is not physically possible therefore the tundish head is not the only contribution to the creation of flow velocity in the regulation region. Instead the total head from mould meniscus up to the tundish level should be considered for stopper regulation curve determination. The liquid falling into the casting channel creates a suction effect explaining why the throttling velocity is greater than $V_{\text {th }}$ calculated using $H$ being only the tundish head.

If considering the total head from tundish meniscus to mold meniscus, as shown in Figure 4, the coefficient of discharge is around 0.75 as mentioned in literature.

The calculated maximum velocity in Figures 3 and 5 exceeds $V_{\text {th }}=4.43 \mathrm{~m} / \mathrm{s}$ $\left(V_{\text {th }}=\sqrt{2 . g . H}\right.$ with $\left.\mathrm{H}=1 \mathrm{~m}\right)$. If the casting channel between the regulation and the mould meniscus was full of steel, then the maximum velocity could reach $5.94 \mathrm{~m} / \mathrm{s}$ for the $1.8 \mathrm{~m}$ total head.

* Technical contribution to the $45^{\text {th }}$ Steelmaking Seminar, May $25^{\text {th }}-28^{\text {th }}, 2014$, Porto Alegre, RS, Brazil. 


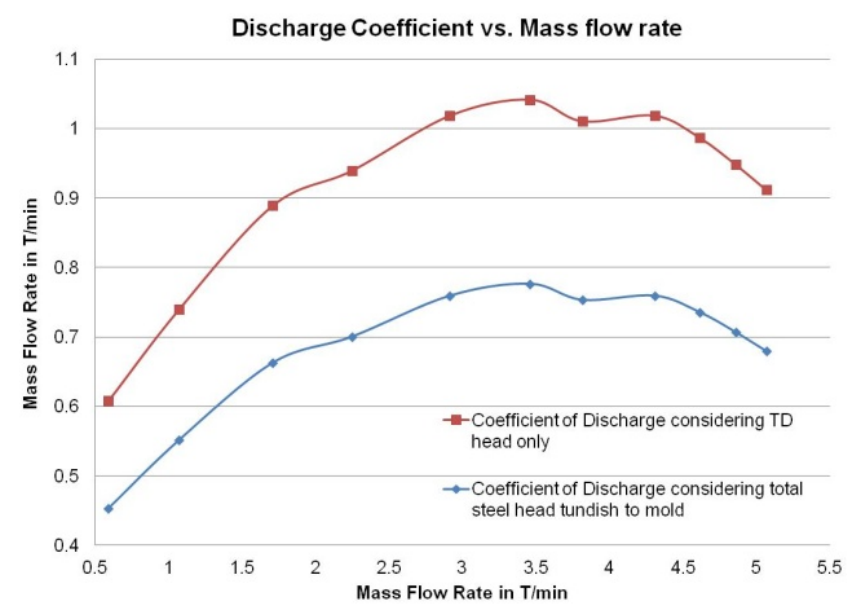

Figure 4. calculated discharge coefficients for tundish and total ferrostatic heads.

Therefore a longer Sub-Entry Nozzle and a deep tundish will cause high velocity in the throttling region and consequently low static pressure as observed in Figure 6.

The low pressure calculated in the vicinity of the throttling region, see Figure 6 , is driving the oxygen bearing gases present inside the refractory to migrate towards the steel/refractory interface.

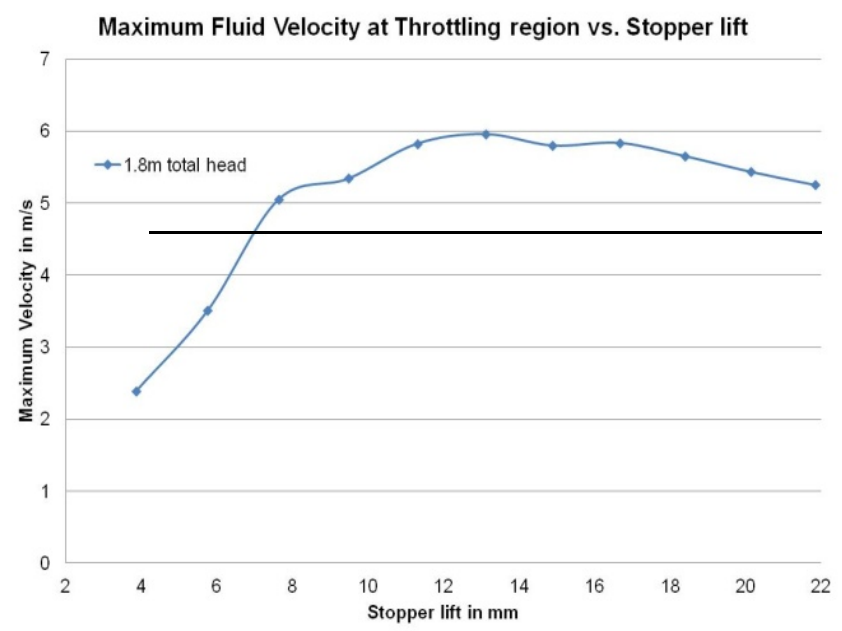

Figure 5. variation of maximum velocity at throttling for 2 different tundish and total ferrostatic heads.
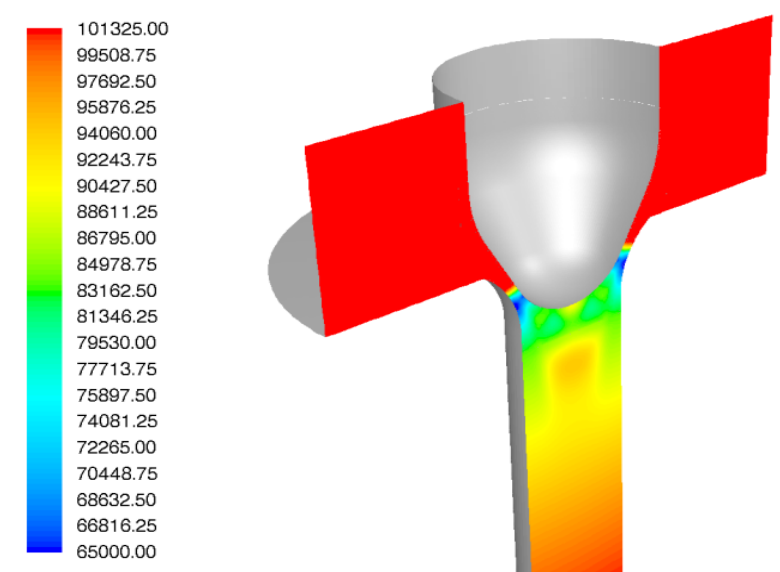

Figure 6. Contours of Absolute Static Pressure expressed in Pa of the liquid steel flowing through the aperture between the stopper nose and the nozzle seat at a given flow rate of $2.5 \mathrm{~T} / \mathrm{min}$.

* Technical contribution to the $45^{\text {th }}$ Steelmaking Seminar, May $25^{\text {th }}-28^{\text {th }}, 2014$, Porto Alegre, RS, Brazil. 
Bolger [1] has calculated $40000 \mathrm{~Pa}$ absolute pressure downstream of the regulation region for a throughput of $2 \mathrm{~T} / \mathrm{min}$.

Poirier et al. [3] have measured 0.2 atmosphere in the regulation region, 0.3 atmosphere at the tip of the stopper nose and 0.4 atmosphere in the detached flow region inside the casting channel just immediately downstream of the regulation annulus.

Figure 7 shows that at $3 \mathrm{~T} / \mathrm{min}$ the minimum pressure is $0.3 \mathrm{~atm}$ for the $1.8 \mathrm{~m}$ total head.

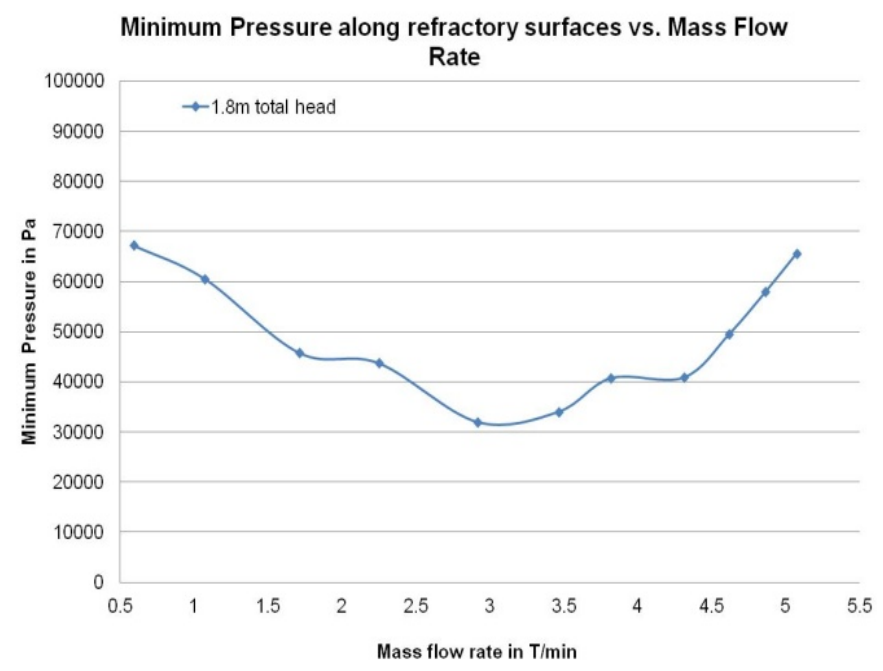

Figure 7. Variation of minimum pressure along the refractory walls.

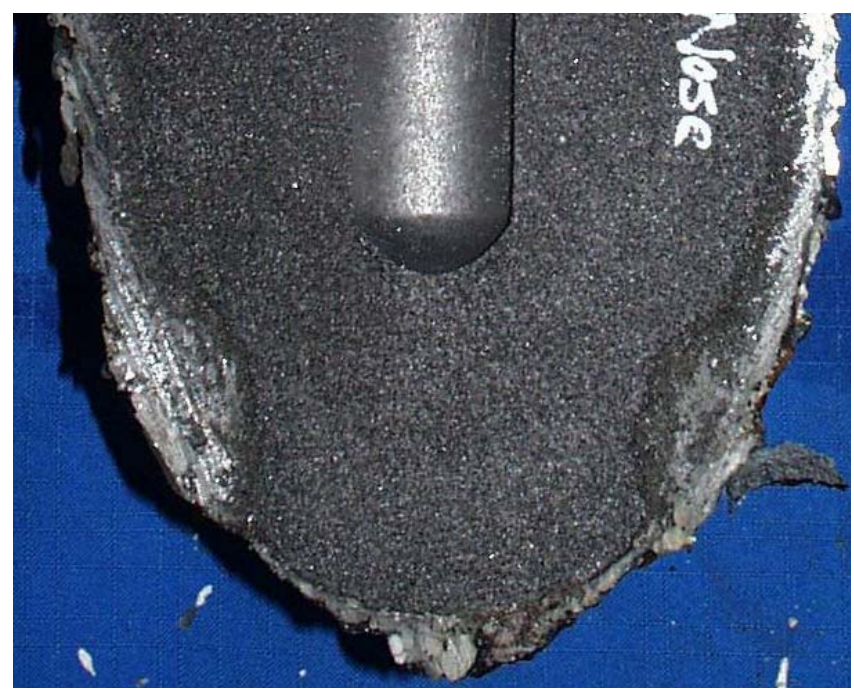

Figure 8. Example of a stopper nose with steel penetration in the regulation region.

Under such low static pressure, when reaching the steel/refractory interface, the oxygen bearing gases present inside the refractory will either promote formation of deposits at the steel/refractory interface or contribute to stopper nose or nozzle seat erosion.

The strong $\mathrm{CO}_{(\mathrm{g})}, \mathrm{SiO}_{(\mathrm{g})}$ and $\mathrm{MgO}_{(\mathrm{g})}$ degassing related to the low pressure will contribute to the re-oxidation of the steel at the interface and leave voids within the refractory structure inside which the steel can infiltrate and then dissolves the carbon from the matrix as seen in Figure 8. Formation of Non Metallic Inclusions along the

* Technical contribution to the $45^{\text {th }}$ Steelmaking Seminar, May $25^{\text {th }}-28^{\text {th }}, 2014$, Porto Alegre, RS, Brazil. 


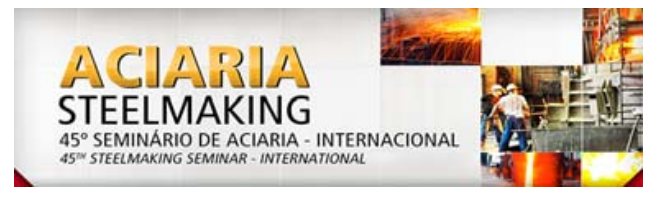

flow regulation wall surfaces can increase friction stresses, thus the coefficient of discharge decreases.

D.Xu, L.J.Heaslip and J.D.Dorricott have designed a new casting channel geometry that includes a flow restriction below the regulation zone to generate flow backpressure and limit the influence of liquid steel falling inside the casting channel. These modifications are described in the "Continuous Casting Nozzle with Pressure Modulator for Improved liquid metal flow regulation" patent US 6,651,899 dated of Nov.25, 2003,

After extensive numerical simulations and numerous water model experiments, the authors have designed and modified the stopper nose shape called Ripple Stopper ${ }^{\mathrm{TM}}$ [4] that decreases the formation of inclusions, minimizes erosion by increasing the minimum pressure.

\subsection{Advanced Stopper Nose Geometry}

Figure 9 is illustrating the geometry of a Ripple Stopper TM which comprises one or several ripples located downstream of the regulation region and an entrance step above the regulation.

The entrance step promotes streamlines bending upstream of the regulation region. The potential energy conversion into kinematic energy is affected; the "Venturi" effect reduced.

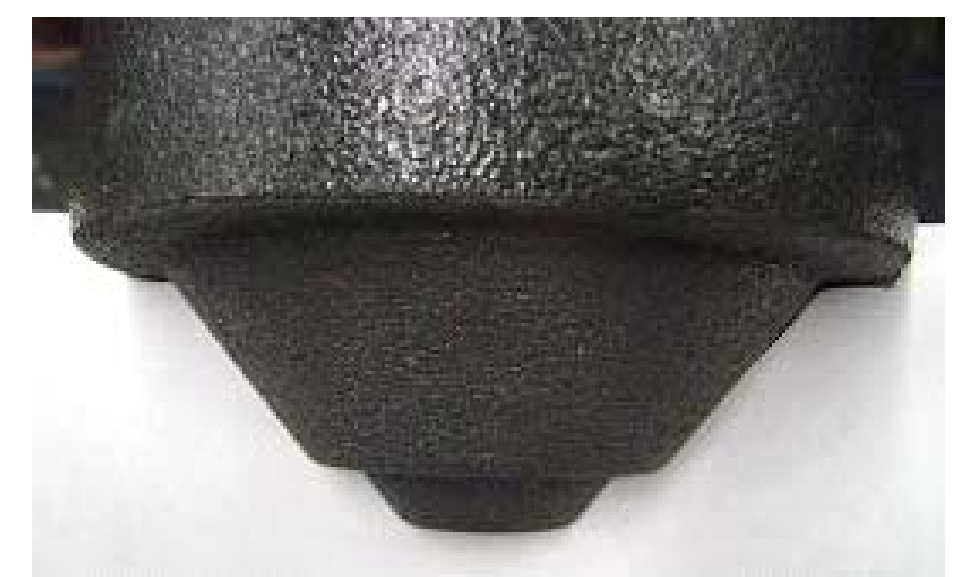

Figure 9. Example of a Ripple Stopper ${ }^{\mathrm{TM}}$ nose.

Consequently the local static pressure will be greater in the regulation region and the maximum velocity reduced as described in the article hereafter.

For the study presented in this article, the tundish head is $0.9 \mathrm{~m}$ and the distance from the bottom of the tundish to the mould meniscus is $0.7 \mathrm{~m}$. The casting channel bore is $70 \mathrm{~mm}$ in diameter.

For a given stopper-nozzle aperture area, there is less steel flow passing through the open gap of an RST (Ripple STopper ${ }^{\mathrm{TM}}$ ) as shown in Figure 10 as expected due to the entrance step influence.

* Technical contribution to the $45^{\text {th }}$ Steelmaking Seminar, May $25^{\text {th }}-28^{\text {th }}, 2014$, Porto Alegre, RS, Brazil. 

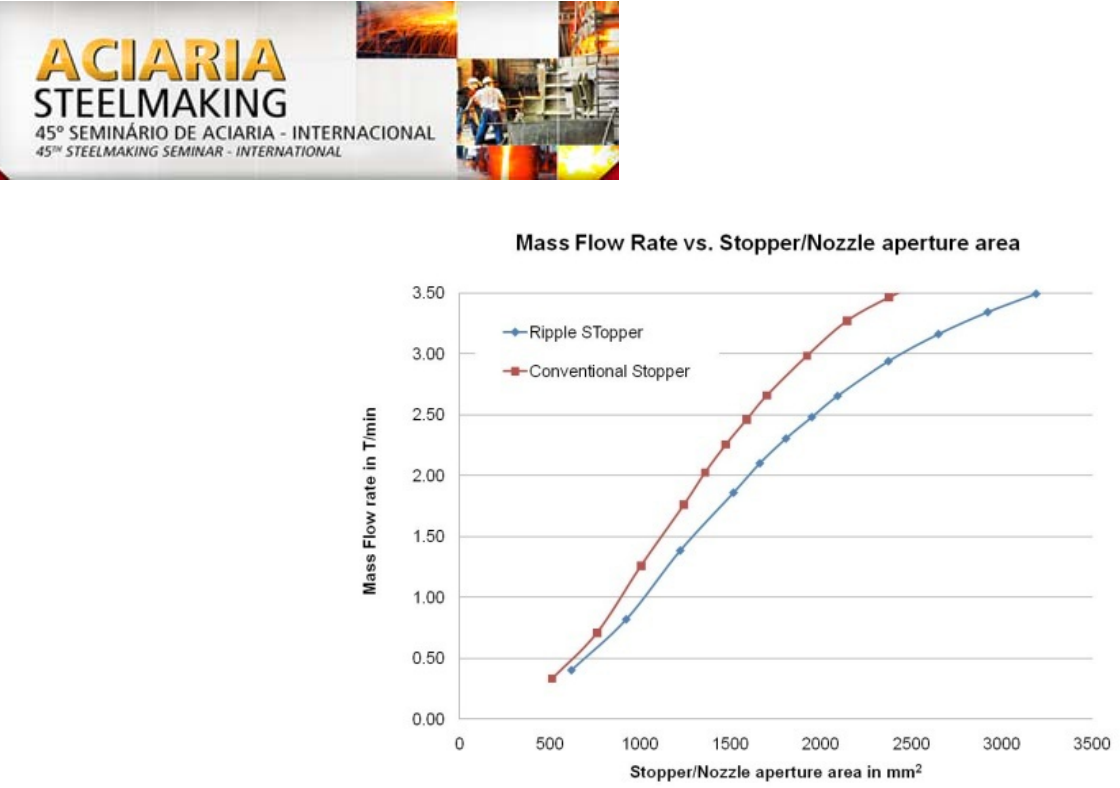

Figure 10. Flow rate versus aperture area for both the Ripple Stopper and the conventional multiradius stopper nose geometries.

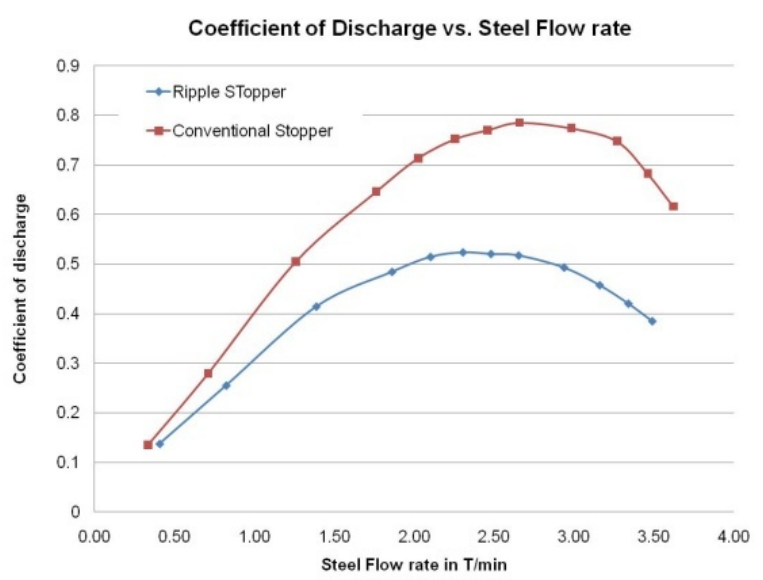

Figure 11. Coefficient of discharge vs. steel flow rate for both the Ripple Stopper ${ }^{\mathrm{TM}}$ and the conventional multi-radius stopper nose geometries.

The coefficient of discharge is then decreased as illustrated in Figure 11. With a smaller coefficient of discharge, i.e. more head losses and more generated turbulence, the stopper flow control is improved due to a smoother regulation curve.

The special stopper nose geometry creates more turbulence that reduces the available potential energy for its conversion into steel velocity. The maximum velocity of the steel flowing through the stopper nozzle aperture is then reduced as shown in Figures 12 and 13.

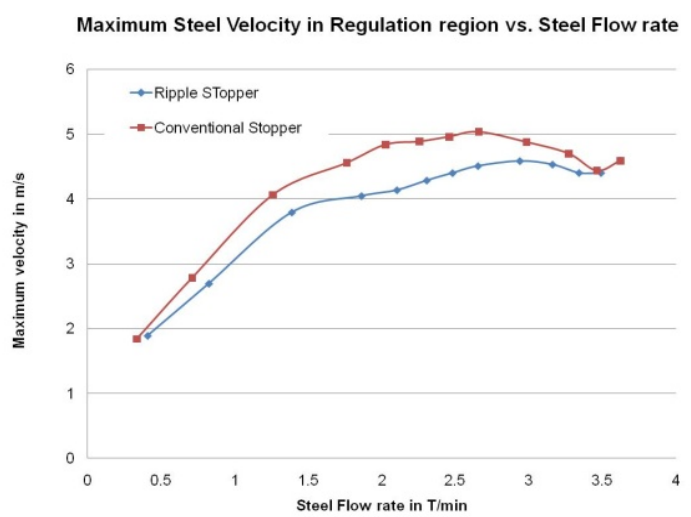

Figure 12. Maximum steel velocity in regulation region for both Ripple Stopper ${ }^{\mathrm{TM}}$ and the conventional multi-radius stopper nose geometries.

* Technical contribution to the $45^{\text {th }}$ Steelmaking Seminar, May $25^{\text {th }}-28^{\text {th }}, 2014$, Porto Alegre, RS, Brazil. 


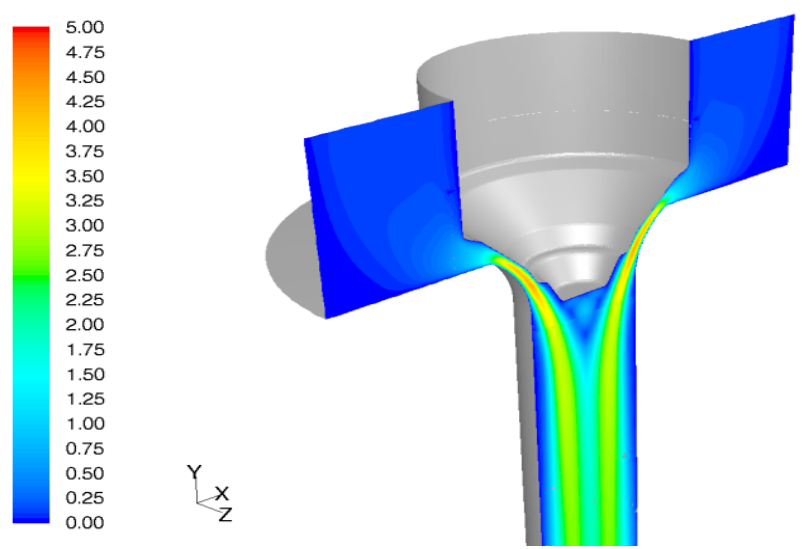

Figure 13. Contours of Velocity Magnitude expressed in $\mathrm{m} / \mathrm{s}$ of the liquid steel flowing through the aperture between the Ripple Stopper ${ }^{\mathrm{TM}}$ nose and the nozzle seat at a given flow rate of $2.5 \mathrm{~T} / \mathrm{min}$.

Vorticity is a measure of the rotation of a fluid element as it moves in the flow field. These rotating fluid elements constitute eddies and swirls that will destabilize the overall mould flow if their kinematic energy is high enough. The Ripple Stopper ${ }^{\mathrm{TM}}$ reduces the formation of these large and powerful vortices and swirls as seen in Figure 14. This particular new nose profile is optimized for throughput between 1 and $2.8 \mathrm{~T} / \mathrm{min}$. Different casting channel geometries and different desired mass flow ranges will required a different optimized stopper nose geometry.

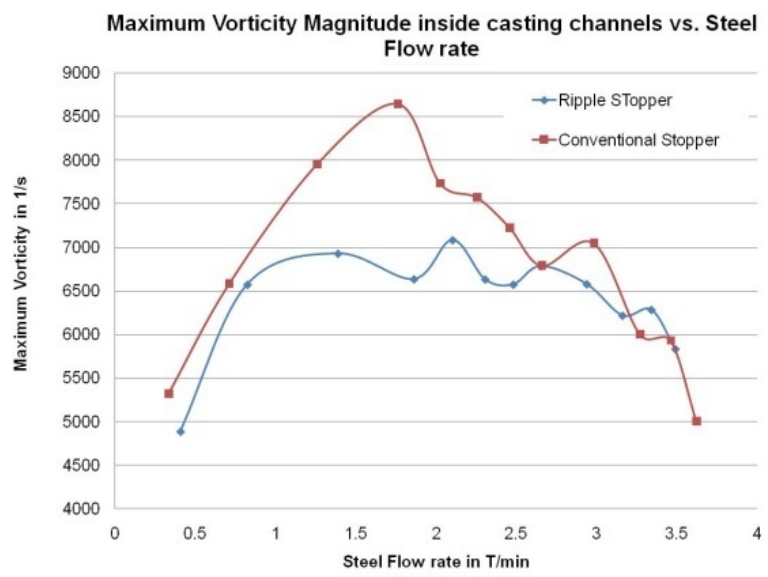

Figure 14. Maximum Vorticity Magnitude for both Ripple Stopper ${ }^{\mathrm{TM}}$ and the conventional multi-radius stopper nose geometries.

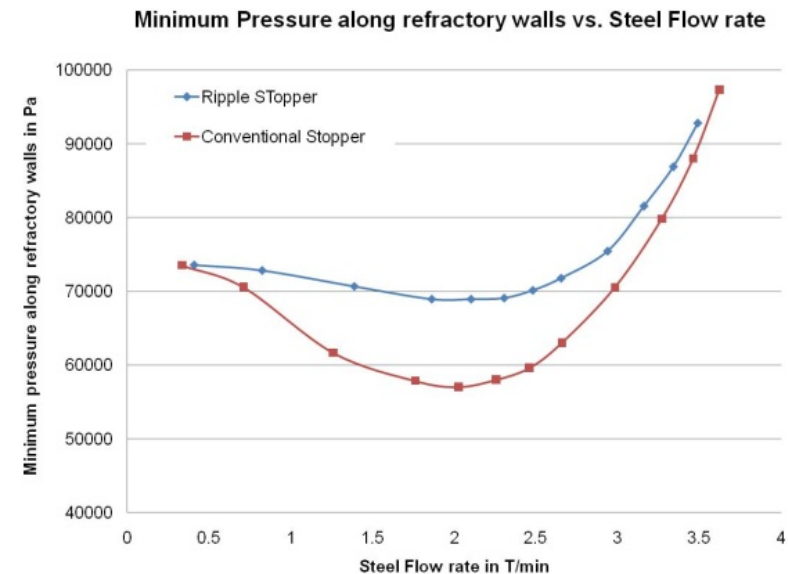

Figure 15. Minimum pressure along refractory walls for both Ripple Stopper ${ }^{\mathrm{TM}}$ and the conventional multi-radius stopper nose geometries.

* Technical contribution to the $45^{\text {th }}$ Steelmaking Seminar, May $25^{\text {th }}-28^{\text {th }}, 2014$, Porto Alegre, RS, Brazil. 


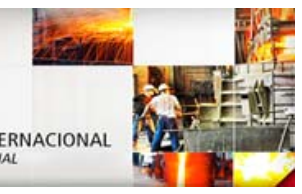

The minimum pressure is increased thus preventing oxygen bearing gases diffusion towards the steel interface, Figures 15 and 16.
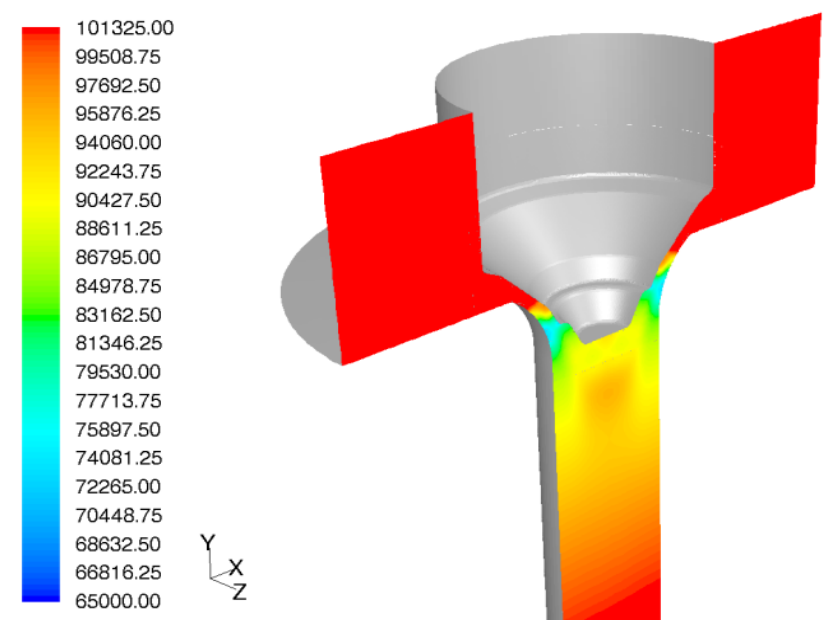

Figure 16. Contours of Absolute Static Pressure expressed in $\mathrm{Pa}$ of the liquid steel flowing through the aperture between the Ripple Stopper ${ }^{\mathrm{TM}}$ nose and the nozzle seat at a given flow rate of $2.5 \mathrm{~T} / \mathrm{min}$.

Formation of clogging or erosion, according to the steel grade chemistry, is expected to be reduced.

In addition, the stopper position does not fluctuate in the presence of cold steel or non-metallic deposition which leads to significant stopper raise at the beginning or at the end of the ladle. These sudden stopper position variations are called flushing. Steel quality is typically downgraded immediately after these large fluctuations.

Plant trial results show the overall performance improvement due to the utilization of the Ripple Stopper ${ }^{\mathrm{TM}}$ compared to a conventional conical stopper.

Figure 17 shows the absence of deposition on the Ripple Stopper ${ }^{\mathrm{TM}} \mathrm{b}$ ). The Ripple Stopper ${ }^{\mathrm{TM}}$ trace, dark blue, seen in Figure 18 is nearly horizontal in the case of this highly clogging sensitive steel grade compared to the other conical stopper traces showing position increases over the 3 heat sequence.
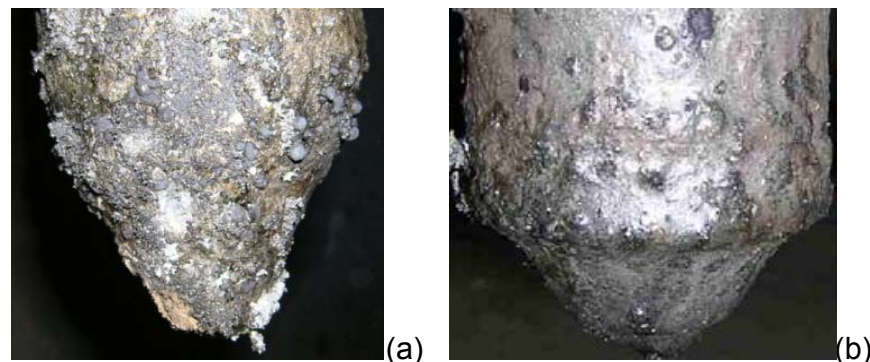

Figure 17. Photographs of stopper nose after use. (a) Conical stopper; and (b) new proposed Ripple Stopper $^{\mathrm{TM}}$

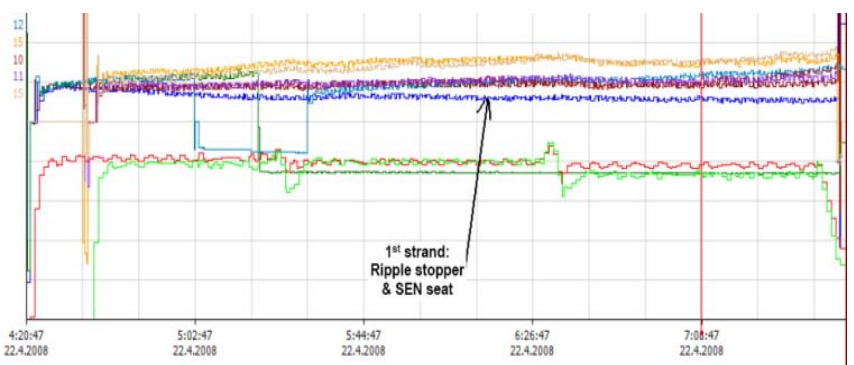

Figure 18. Stopper traces for a 3 heat sequence of highly sensitive clogging steel grade.

* Technical contribution to the $45^{\text {th }}$ Steelmaking Seminar, May $25^{\text {th }}-28^{\text {th }}, 2014$, Porto Alegre, RS, Brazil. 

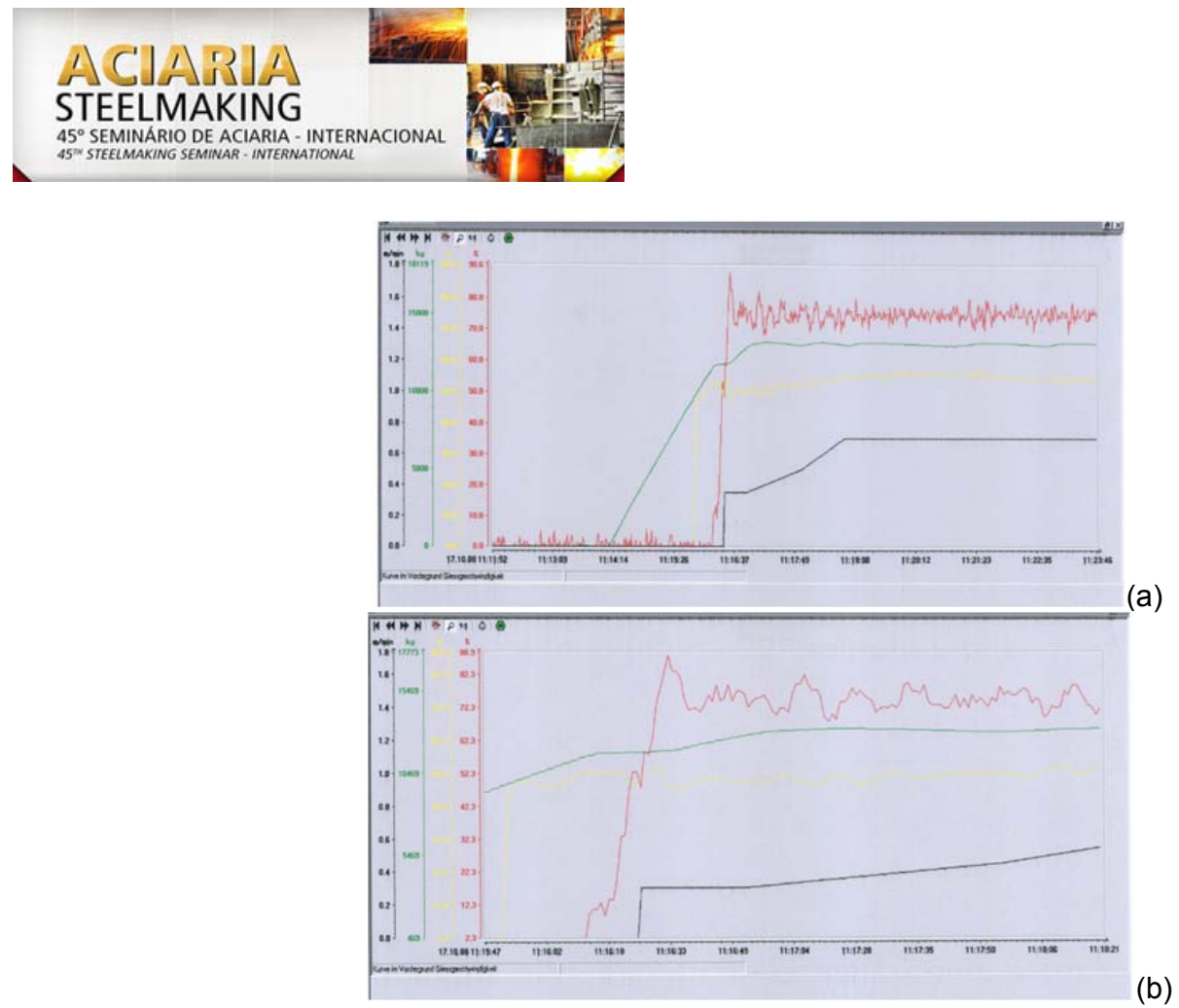

Figure 19. Stopper traces -Ripple Stopper ${ }^{\mathrm{TM}}$. (a) Conventional stopper; and (b) stainless steel grade.

The suppression of the sudden stopper position change results in a smoother mould level as seen in Figure 19. With the Ripple Stopper ${ }^{\mathrm{TM}}$, Figure 19a, the mould level fluctuates at a higher frequency but with lower amplitude. On the contrary, the current stopper produces less frequent mould level fluctuations but at higher amplitude, sees Figure 19b.

Several steel plants are trying to achieve similar results by inducing electromechanical oscillations through the stopper rigging; this is also known as dithering.

The Ripple Stopper ${ }^{\mathrm{TM}}$ was developed after understanding the stopper flow regulation using CFD tools. This new advanced design reduces clogging in the regulation region by increasing the minimum pressure and by reducing the strength of the large fluctuations produced in the regulation region. This translates to a better mould level control, improved mold powder melting and a reduction of clogging sensitivity.

\subsection{Tundish Gate Flow Regulation}

One other way to control steel flow from the tundish to the mould is to use a tundish slide gate system. This is a proven, reliable and efficient flow control method. It is particularly adapted to long sequence casting. This is because certain components of the slide gate can be changed in case of either erosion or clogging, which alters steel flow control and participates to poor mould level control.

Due to clogging potential, tundish gate generally operates in highly throttled position after the initial mold fill, which causes severe steel flow streamlines bending, flow separation and consequently flow asymmetry downstream of the throttling region. This flow asymmetry inside the casting channel can be related to mould bias flow which can be associated with mould powder entrapment by either vortexing near the immerged nozzle or by the formation of one side strong unstable wave, Ozgu [5] and $\mathrm{Xu}[6]$.

To correct the flow asymmetry generated by the slide gate throttling, special bore designs such as in patent \# US 6,425,505 or JP08294757 and port geometry as described in patents WO 2004/082871 and WO 2005/049249 have been developed over the years by many researchers including the authors.

* Technical contribution to the $45^{\text {th }}$ Steelmaking Seminar, May $25^{\text {th }}-28^{\text {th }}, 2014$, Porto Alegre, RS, Brazil. 


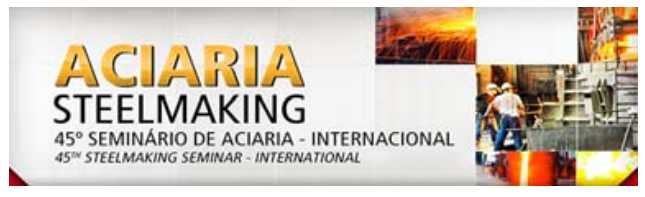

To better understand the tundish gate regulation, both water model and numerical simulations of liquid steel flowing from a tundish to a mould were considered. The tundish slide gate throttling plate diameter was fixed at $70 \mathrm{~mm}$. In the first case, the tundish head was fixed at $1 \mathrm{~m}$, the tundish nozzle was $0.3 \mathrm{~m}$ tall and the distance between the mould meniscus and the throttling plate was $0.7 \mathrm{~m}$. For the second case, the tundish head was $1.2 \mathrm{~m}$ and the total ferrostatic head $1.9 \mathrm{~m}$. In both cases, the distance from the tundish sliding gate plate to the meniscus is $0.7 \mathrm{~m}$. The theoretical tundish gate flow regulation curves were determined by CFD modeling. Similar to the stopper regulation system, an S-curve was computed for both cases, as shown in Figure 20.

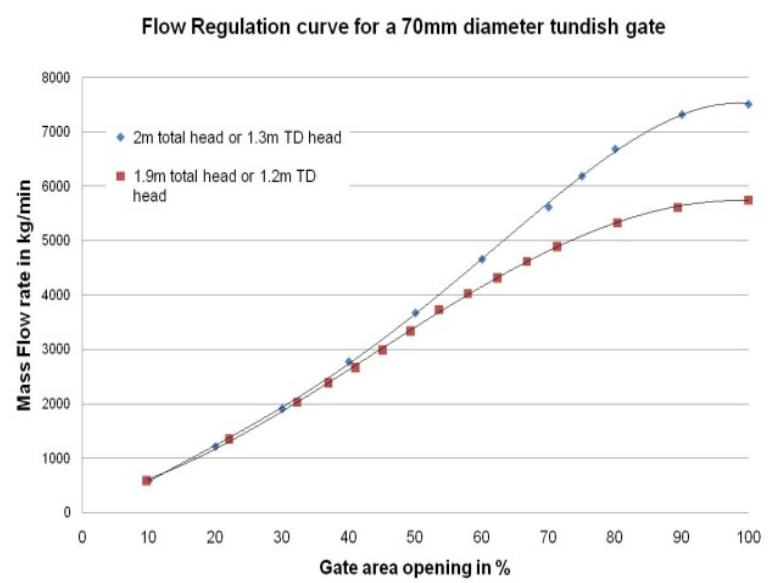

Figure 20. Flow regulation curve for a $70 \mathrm{~mm}$ throttling plate and 2 different tundish ferrostatic heads and 2 different total heads.

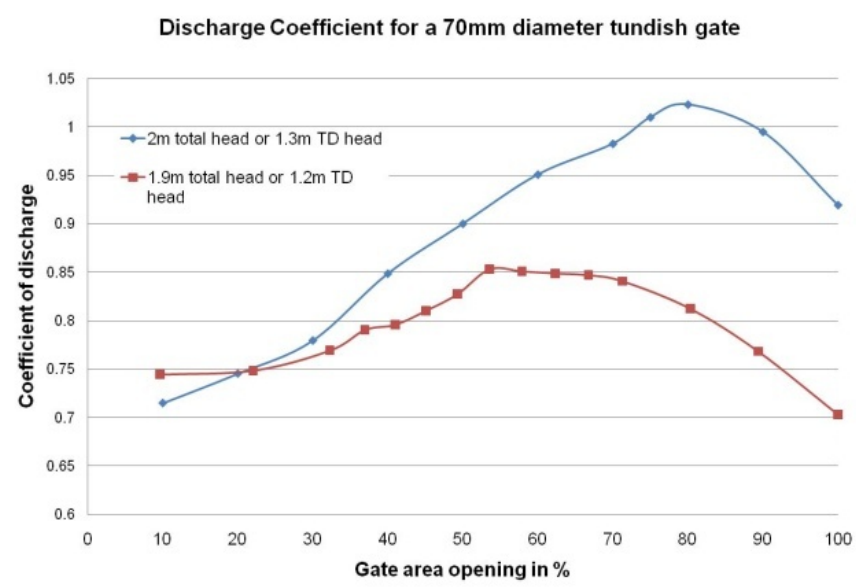

Figure 21. Coefficient of discharge for a $70 \mathrm{~mm}$ throttling plate and 2 different tundish ferrostatic heads and 2 different total heads.

For a small tundish gate opening of up to $30-40 \%$ open area, the friction losses are controlling the steel flow rate, Figures 20 and 21.In this case, both configurations have the same distance between the regulation region and the mold meniscus. At higher gate opening, the difference in tundish head can explain the difference between the 2 curves.

The bore diameter of the sub-entry shroud located downstream of the throttling only influences the maximum flow rate at higher gate opening. If clogging occurs in a small bore shroud, friction losses will increase and the discharge coefficient will

* Technical contribution to the $45^{\text {th }}$ Steelmaking Seminar, May $25^{\text {th }}-28^{\text {th }}, 2014$, Porto Alegre, RS, Brazil. 
decrease quickly if the gate area opening is greater than $50 \%$ in the case of a smaller shroud bore; $70 \mathrm{~mm}$ for the red curve and $80 \mathrm{~mm}$ for the blue curve in Figure 21.
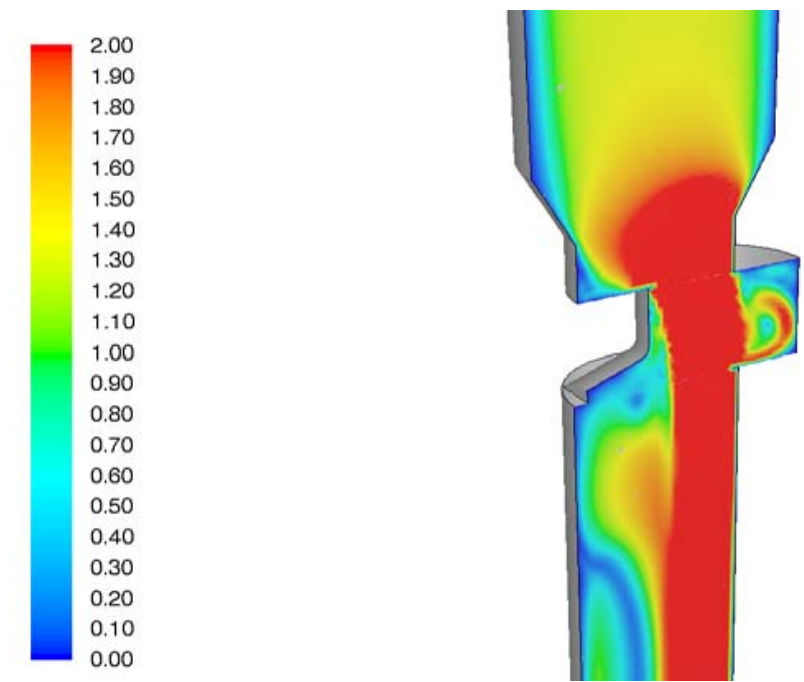

Figure 22. Contours of Velocity Magnitude expressed in $\mathrm{m} / \mathrm{s}$ of the liquid steel flowing through the open area of a $70 \mathrm{~mm}$ diameter throttling plate at a given flow rate of $3 \mathrm{~T} / \mathrm{min}$.

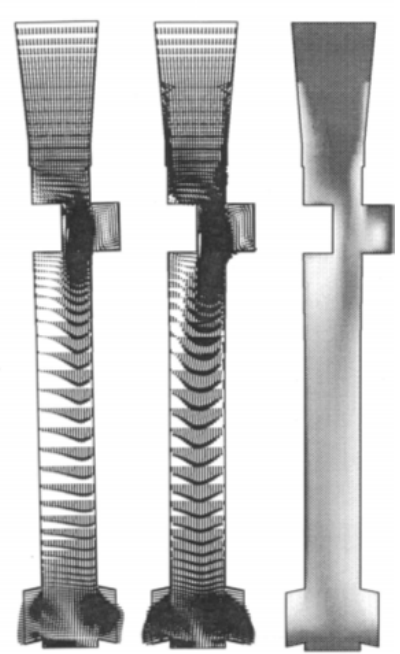

Figure 23. Flow Pattern in a Slide-Gate Nozzle [7]. (a) Without argon; (b) With argon injection (10\% in volume fraction); and (c) Volume fraction (lighter areas have more argon).

With a conventional tundish slide gate plate system, whenever the throttling plate is not fully open, the fluid does not fully utilize the shroud bore, Figure 22 . Inside the large recirculation areas, powerful eddies and unstable flow structure are generated along with the gas bubbles gathering. The mould flow will be unstable and the jet distribution will be biased.

Thomas et al. [7] have shown that gas injection promotes flow diffusion inside the shroud, Figure 23.

The computed maximum velocity in the throttling region, plotted in Figure 24, shows that the total ferrostatic head between the tundish meniscus to the mould meniscus should be considered instead of only the tundish head. For a $2 \mathrm{~m}$ total ferrostatic head, $V_{\text {th }}$ is around $6.3 \mathrm{~m} / \mathrm{s}$ but only $5 \mathrm{~m} / \mathrm{s}$ for $1.2 \mathrm{~m}$ of tundish head

* Technical contribution to the $45^{\text {th }}$ Steelmaking Seminar, May $25^{\text {th }}-28^{\text {th }}, 2014$, Porto Alegre, RS, Brazil. 

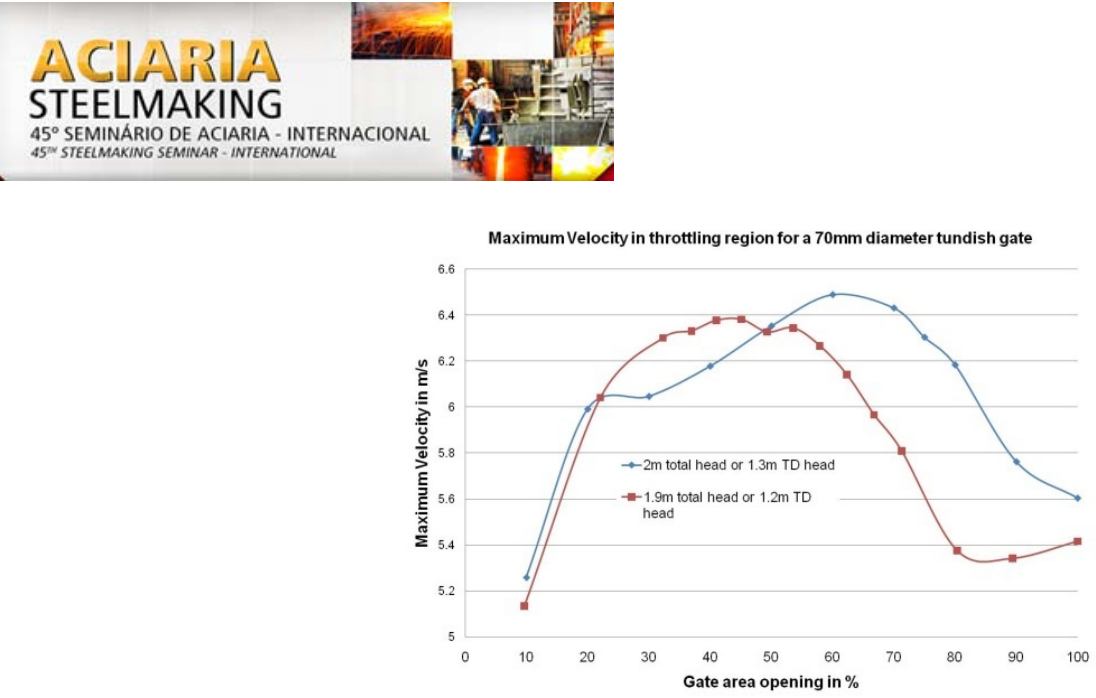

Figure 24. Maximum liquid steel velocity through a $70 \mathrm{~mm}$ throttling plate and 2 different tundish ferrostatic heads and 2 different total heads.

Along with various researchers [6,8], D.Xu, L.J.Heaslip, J.D.Dorricott have developed a patented, \# US 6,783,088 dated on Aug.31 2004, new casting channel geometry to re-align the flow streamlines, to reduce the highly biased flow both up- and downstream of the throttling region.

This new casting channel design is designated as Offset Bore system in this article. The offset can be designed in either the top plate see Figure 25 or the tundish well nozzle see Figure 26.

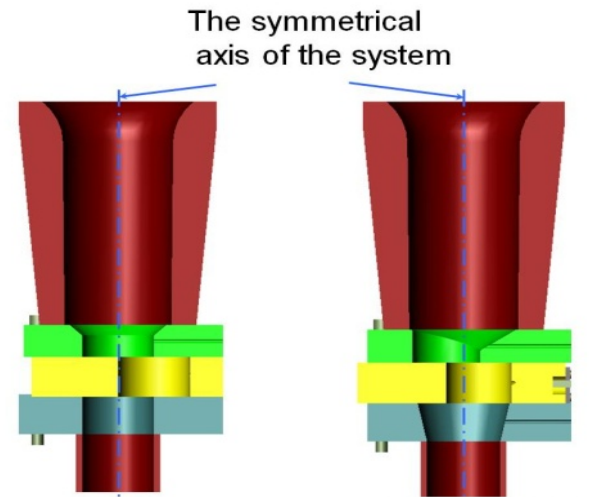

(a) Current Stack-up

(b) Offset Stack-up

The Sectional view of the Flow Channels at $50 \%$ open:

Figure 25. Sectional 3D views of the Offset bore (b) compared to a typical casting channel (a) at $50 \%$ gate open.
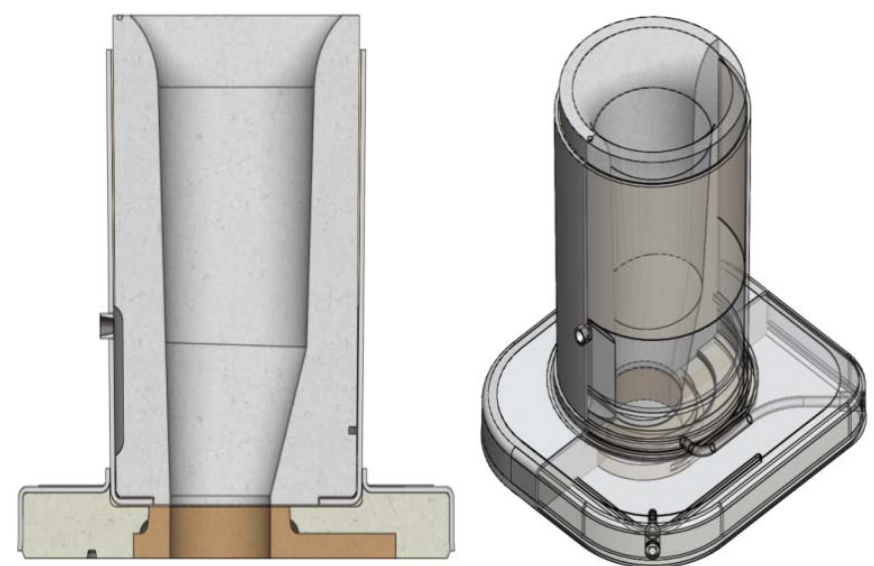

Figure 26. Sectional 3D views of the Offset bore designed in the tundish nozzle section.

* Technical contribution to the $45^{\text {th }}$ Steelmaking Seminar, May $25^{\text {th }}-28^{\text {th }}, 2014$, Porto Alegre, RS, Brazil. 


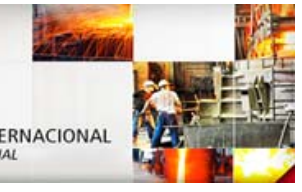

With the offset bore, the flow streamlines are now coincident with symmetrical axis of the lower casting channel, as illustrated in Figure 27.

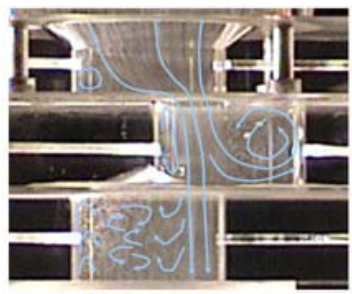

(a) Current Stack-up

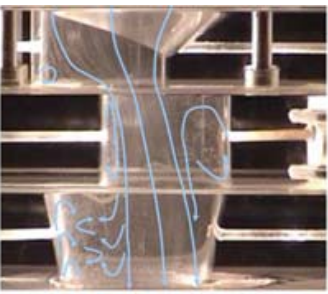

(b) Offset stack-ups

Flow patterns in current stack-up (a) and Offset stack-up (b) Throughput: $4 \mathrm{Ton} / \mathrm{min}$

Figure 27. Water model results comparing the flow pattern in the gate regulation region produced by a conventional a) and an Offset Bore b) designs at $4 \mathrm{~T} / \mathrm{min}[8]$.
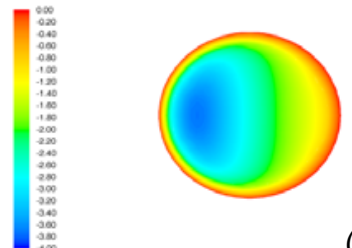

(a)
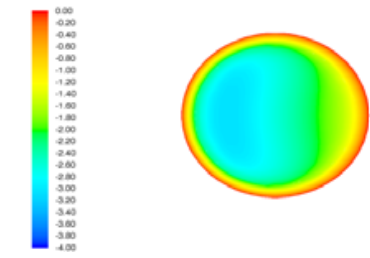

(b)

Figure 28. Vertical Velocity distribution inside the shroud bore along a line taken in the central plane above the ports produced by a conventional a) and an Offset Bore b) designs at 4T/min

The Offset Bore design promotes flow diffusion inside the shroud bore. The velocity is more evenly distributed as seen in Figures 29 and 30. Bias flows observed in the mould are reduced.

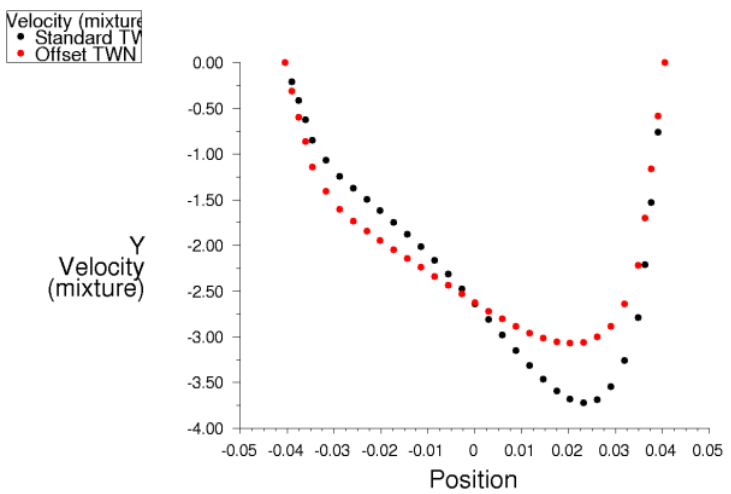

Figure 29. Velocity distribution $(\mathrm{m} / \mathrm{s})$ inside the shroud bore along a line taken in the central plane above the ports.

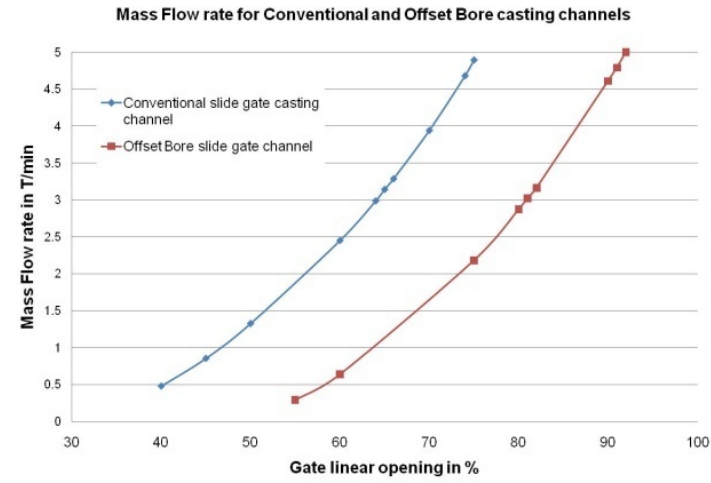

Figure 30. Tundish gate regulation curve for a conventional gate, blue and an Offset Bore channel, red.

* Technical contribution to the $45^{\text {th }}$ Steelmaking Seminar, May $25^{\text {th }}-28^{\text {th }}$, 2014, Porto Alegre, RS, Brazil. 
The tundish gate regulation curve obtained with an offset bore gate is similar to what is computed with a conventional tundish slide gate. If the gate initial position is not corrected as in Figure 30, the difference is in fact the offset.

With the Offset Bore casting channel, the velocity distribution is improved with downstream and upstream of the throttling region, as depicted in Figure 31.

The Offset bore casting channel reduces the "dead" flow regions, inside which turbulence is not sufficient to prevent deposition of formation of non-metallic products along the refractory/steel interface, Figure 32.
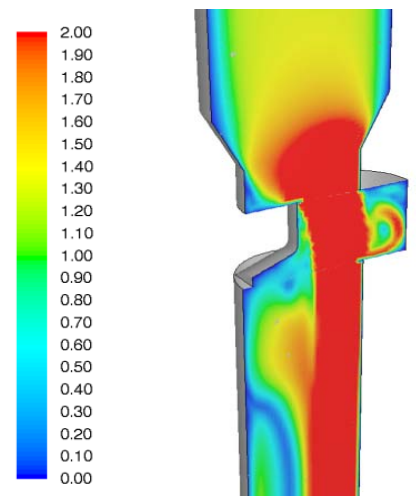

(a)

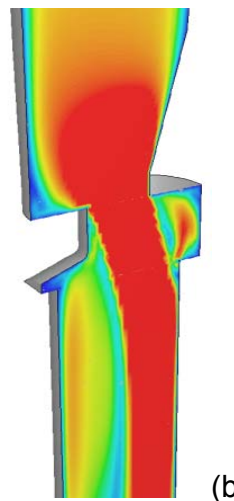

(b)

Figure 31. Vertical Velocity distribution inside the shroud bore along a line taken in the central plane above the ports. produced by a conventional (a) and an Offset Bore (b) designs at 4T/min.
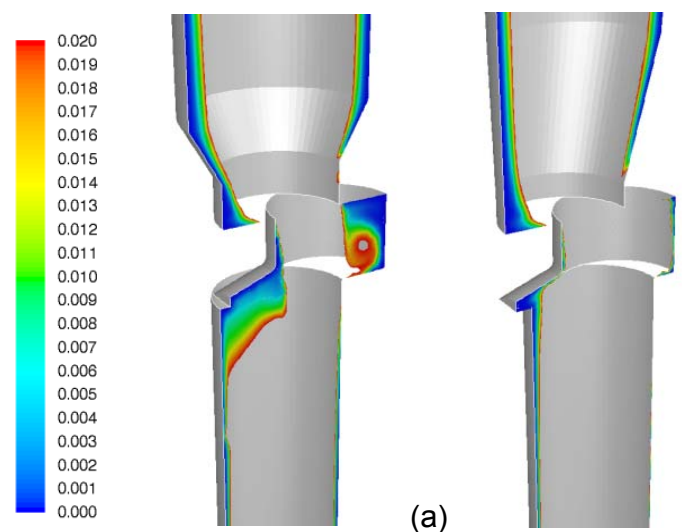

(b)

Figure 32. Iso-surface of velocity at $0.05 \mathrm{~m} / \mathrm{s}$ coloured by turbulence kinetic energy expressed in $\mathrm{m}^{2} / \mathrm{s}^{2}$ illustrating the high clogging prone regions produced by a conventional (a) and an Offset Bore (b) designs at $4 \mathrm{~T} / \mathrm{min}$.

As predicted by numerical simulation, the non-metallic deposition has been significantly reduced as illustrated in Figures 32 and 33 . Head losses, due to clogging, are now limited. The tundish flow regulation is then more predictable throughout longer casting sequences. With an improved fluid velocity distribution inside the lower shroud, mould bias flow reduction is also expected.
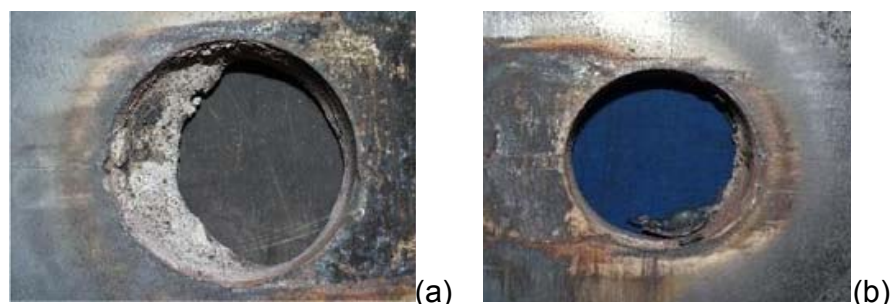

Figure 33. Deposition inside the throttling plate with a conventional slide gate plate (a) and with the Offset Bore channel design (b).

* Technical contribution to the $45^{\text {th }}$ Steelmaking Seminar, May $25^{\text {th }}-28^{\text {th }}, 2014$, Porto Alegre, RS, Brazil. 

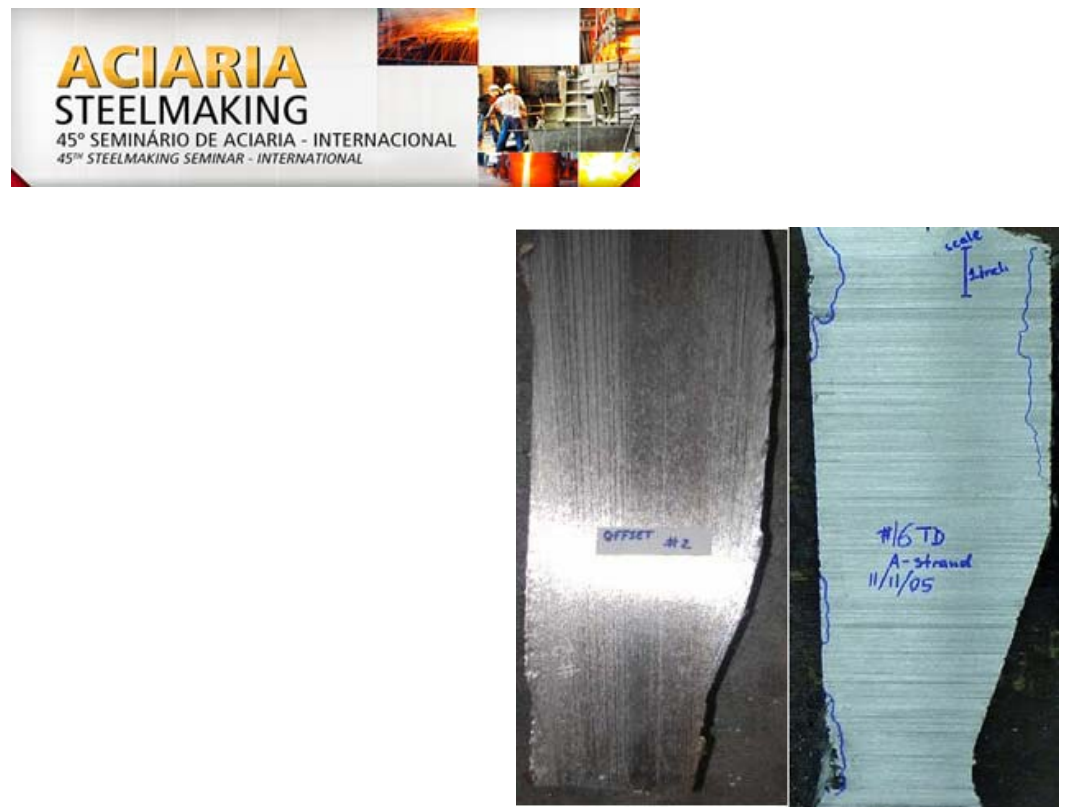

Figure 34. Two Examples of steel pins with limited deposition removed from an Offset Bore tundish well nozzle.

The steelmaker using the offset bore casting channel, from which the tundish nozzle steel pins seen in Figure 34, has extended the tundish sequence length by 2 heats due to clogging reduction in the upper region of the tundish gate.

\section{CONCLUSIONS}

Optimal flow control between tundish to mould is critical to insure high quality steel casting. When either a stopper rod or a tundish slide gate is used, the regulation curve is S-shaped.

New stopper nose geometry has been developed with the aid of numerical simulations and a deep understanding of stopper flow control. Higher minimum pressure and reduced turbulence are achieved with the use of the Ripple Stopper ${ }^{\mathrm{TM}}$. The refractory performance is improved as well as the mould level as confirmed by steel plant results.

With the new tundish gate casting channel, the liquid steel flowing through the throttling plate is more evenly distributed inside the shroud. This leads to a better flow distribution throughout the nozzle outlet. Mould bias flow is then reduced. The clogging potential inside the a casting channel is also reduced allowing longer casting sequence without steel quality downgrades.

\section{REFERENCES}

1 Bolger D. Stopper rod and submerged nozzle design and operation in continuous casting. In: AIME. $77^{\text {th }}$ Steelmaking Conference Proceedings; 1994, Warrendale, USA. AIME; 1994. p.531-537.

2 Bergman L. Measurement Prediction and Control of Steel Flows in the Casting Nozzle and Mould [master's thesis]. Lulea: Lulea University of technology; 2006.

3 Poirier J, Guiban MA, Blumenfeld Ph, Boher M, Bourrier Ph. Contribution of refractories to the steel quality and cleanliness. La revue de la Metallurgie-CIT. 2000;October:11451159.

4 Richaud J, Heaslip LJ, Dorricott JD. US patent \# 7,581,663 B2, September 2009.

5 Ozgu MR, Sattler WE, Farlow CA, Lawrence LJ. Conversion of burns harbor's slab casters from lift to quick SEN changing, 2003 ISSTech, p p31-39

6 Xu D, Heaslip LJ, Dorricott, JD. A Study of tundish-to-mould fluid flow for enhanced tundish slide-gate performance and reduced alumina clogging. In: ISS. 85th Steelmaking Conference Proceedings; March 2002. Nashville: ISS. p.390-405.

* Technical contribution to the $45^{\text {th }}$ Steelmaking Seminar, May $25^{\text {th }}-28^{\text {th }}, 2014$, Porto Alegre, RS, Brazil. 
7 Thomas BG, Dennisov A, Bai H. Behavior of Argon Bubbles during Continuous Casting of Steel. In: ISS. Steelmaking Conference Proceedings; April 1997. Chicago: ISS. p.375384.

8 King PD, Heaslip LJ, Xu D, Dorricott JD, Robinson QK. Tundish slide-gate system for enhanced performance, reduced alumina clogging, and extended string length. In: ISS. ISSTech2003 Conference Proceedings; 2003. Warrandale: ISS. Vol. Electric Furnace and Steelmaking. p.265-282.

* Technical contribution to the $45^{\text {th }}$ Steelmaking Seminar, May $25^{\text {th }}-28^{\text {th }}, 2014$, Porto Alegre, RS, Brazil. 